\title{
The Role of the Local Hadley Circulation over the Western Pacific on the Zonally Asymmetric Anomalies over the Indian Ocean
}

\author{
Yoshiyuki KAJIKAWA, Tetsuzo YASUNARI \\ Institute of Geoscience, University of Tsukuba, Tsukuba, Japan \\ and \\ Ryuichi KAWAMURA \\ Department of Earth Science, Toyama University, Toyama, Japan \\ (Manuscript received 4 February 2002, in revised form 6 December 2002)
}

\begin{abstract}
The onset processes of the zonally asymmetric anomalies of convection and sea surface temperature (SST) over the tropical Indian Ocean are investigated with considering seasonal evolution, and interannual variability, of the large-scale convection anomalies in the Asian summer monsoon, using outgoing longwave radiation (OLR), SST, and NCEP/NCAR reanalysis data. This asymmetric pattern of the convection anomalies is particularly dominated in boreal autumn. Some recent studies have noted that these anomalies, based on the atmosphere-ocean coupling phenomenon, can be developed and maintained by itself.

The time evolution shows that the eastern part of the zonally asymmetric anomalies over the Indian Ocean lead the western part of those. In July, the negative SST anomalies and positive OLR anomalies first appeared off the Sumatra coast, and southeasterly wind anomaly accelerated the climatological southeasterly wind along the west coast of Sumatra. This southeasterly wind acceleration provide a SST cooling over the southeastern Indian Ocean, and play a role in triggering of the zonally asymmetric anomalies in the following autumn. It is suggested that this southeasterly wind acceleration over the southeastern Indian Ocean is closely linked to the meridionally asymmetric anomalies of convection, between the maritime continent and the South China Sea/Philippine Sea (SCS/PS). That is, the intensification of the local Hadley circulation over the western Pacific associated with the enhanced convection over the SCS/PS, and suppressed convection over the maritime continent, is found to be a clear precursory signal of the zonally asymmetric anomalies over the Indian Ocean. It has also been noted that the convection anomalies over the southern and northern parts of the meridionally asymmetric anomalies over the western Pacific are not always the opposite sign, and seem to have different interannual variability respectively. It is likely that the former might be strongly influenced by the ENSO, through the Walker circulation anomalies and the latter might be affected by the modulation of the intraseasonal variation of the Asian summer monsoon. The seasonality of the zonally asymmetric anomalies is also suggested from the occurrence of the intensification of the local Hadley circulation in boreal summer.
\end{abstract}

Corresponding author and present affiliation: Tetsuzo Yasunari, Hydrospheric Atmospheric Research Center, Nagoya University, Nagoya 4648601, Japan.

E-mail: yasunari@ihas.nagoya-u.ac.jp

(C) 2003, Meteorological Society of Japan

\section{Introduction}

Tropical convection over the Indian Ocean has large seasonal variability associated with the seasonal evolution of the Asian/Australian monsoon (Fig. 1). The convection over the 
(a) $D J F$

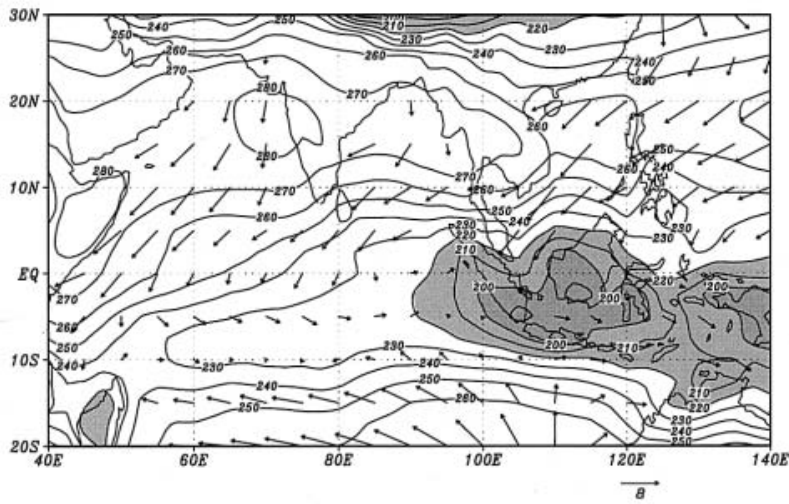

(c)

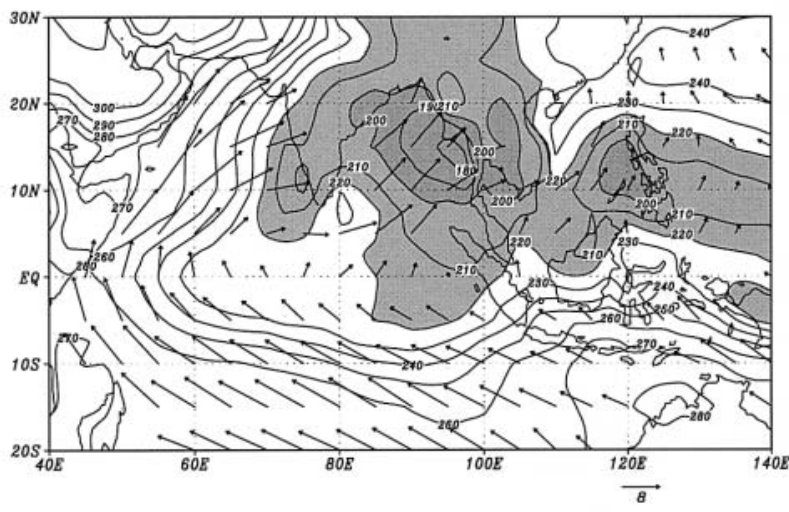

(b)

$M A M$

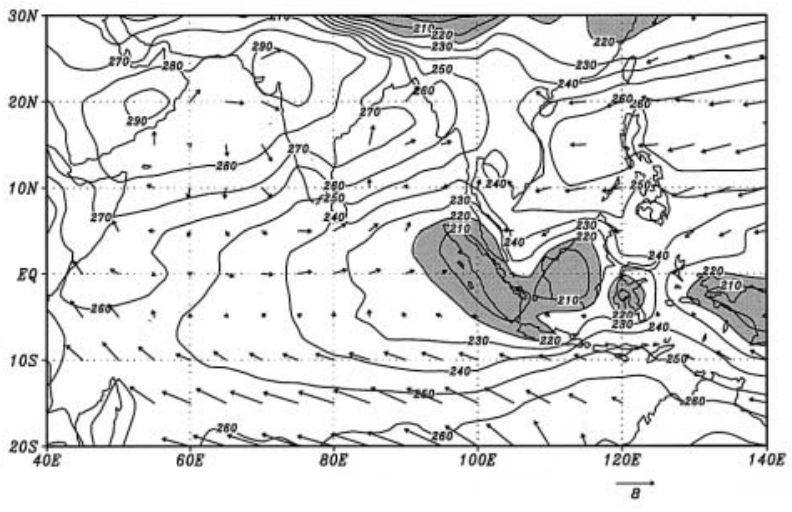

(d)

SON

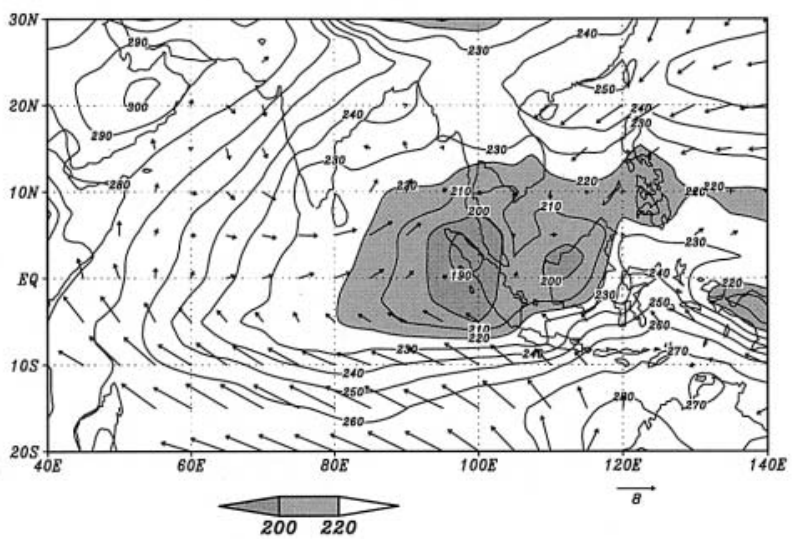

Fig. 1. Climatological seasonal mean OLR and $1000 \mathrm{hPa}$ wind based on the 24-year period from 1974-1997. (a) DJF, (b) MAM, (c) JJA, (d) SON. Contour interval is $10 \mathrm{~W} / \mathrm{m}^{2}$ and unit is $8 \mathrm{~m} / \mathrm{s}$.

Indian Ocean also has large interannual variability, which is strongly coupled with the interannual variability of sea surface temperature (SST), and plays an important role in regulating the strength of the Asian monsoon as suggested by several studies (Meehl 1987; Meehl 1997; Chandrasekar and Kitoh 1998). Those convection, and SST anomalies over the Indian Ocean, are closely related to anomalous weather and climate condition in the surrounding regions, e.g., eastern Africa and Indonesia, through the modulation of atmospheric zonal circulation (Cambrlin 1995; Birkett et al. 1999).

The interannual variability of the Indian Ocean SST was studied by a number of researchers. Villwock and Latif (1994) found from the result of an empirical orthogonal function
(EOF) analysis of the Indian Ocean SST, that temporal score of the dominant mode correlate with the southern oscillation index (SOI), and spatial pattern of that is characterized by a broad-scale ocean basin anomaly, with a uniform sign. Many other studies pointed out that those anomalies over the Indian Ocean have some relevance to the ENSO (Cadet 1985; Yasunari 1987; Latif and Barnett 1995; Tourre and White 1995; Potemra and Lukas 1999; Chambers et al. 1999; $\mathrm{Yu}$ and Rienecker 1999; Klein et al. 1999). Meanwhile, Nicholls (1989) found the SST difference pattern between the eastern and central Indian Ocean, and noted that it is independent of the ENSO by investigating Australian rainfall. Saji et al. (1999) extracted a dipole structure of SST anomalies 
over the Indian Ocean using an EOF analysis. The spatial pattern of this dipole mode is represented by the SST difference between the eastern and western Indian Ocean and very similar to that shown by Nicholls (1989). They showed a weak correlation between the dipole mode index and the Niño 3 SST anomaly, and emphasized that this mode is probably independent of the ENSO event. To summarize these previous studies, the interannual variability of the Indian Ocean SST includes both the broad-scale warming pattern connected with the ENSO, and the dipole pattern between the eastern and the western Indian Ocean, which may be presumably independent of the ENSO.

On the other hand, few observational studies have been devoted to interannual variability of convection over the Indian Ocean, unlike the study of SST anomalies, because of the absence of long term dataset until recently. Saji et al. (1999) found the zonally asymmetric anomalies of precipitation associated with SST dipole event, as seen in the close connection between floods in east Africa and drought in Indonesia, and weakening or reversal of the Walker circulation over the Indian Ocean. Webster et al. (1999) also focused on the same dipole event during 1997-1998, and indicated the zonally asymmetric anomalies of SST, sea surface height (SSH), outgoing longwave radiation (OLR) and strong easterly anomaly over the Indian Ocean. In this manner, these zonally asymmetric anomalies over the Indian Ocean seemed to appear as an atmosphere-ocean interaction.

However, some problems of this phenomenon has remained unresolved, especially on the triggering mechanism, and its seasonality (Anderson 1999). The questions may be summarized mainly in the following two points; One, is whether these asymmetric anomalies are induced by some external forcing or by purely internal dynamics, in other words, whether these anomalies are associated with the ENSO, or independent of the ENSO. Webster et al. (1999) concluded that the zonally asymmetric anomalies during 1997-1998 might be due to internal dynamics, including the atmosphere-ocean interaction rather than the external influence, although the strong El Niño event occurred in the equatorial Pacific. Saji et al. (1999) and
Iizuka et al. (2000) also stressed the dipole mode is independent of the ENSO based on a weak correlation between dipole mode index, and SOI or Niño 3 SST anomaly, as mentioned above. Meanwhile, Ueda and Matsumoto (2000) and Ueda (2001), postulated that these asymmetric anomalies are likely to be produced by the coupling process, between the Walker circulation modulated by the El Niño event and the climatological monsoon circulation, in the case of 1997/1998. The other question may be why these asymmetric anomalies are initiated in boreal summer and develop during boreal autumn, which has been indicated from some results such as seasonally-stratified composite analysis. Thus, the onset processes, the triggering mechanism and the seasonality of this phenomenon have been remained as an open question.

The purposes of this paper are, first, to reexamine the zonally asymmetric anomalies over the Indian Ocean, based on a statistical analysis of interannual convection anomalies, and then, to describe its evolution and finally to present an onset processes with consideration of seasonal evolution, and interannual variability of the large-scale convective activity in the Asian summer monsoon. A possible relationship between the onset processes of the zonally asymmetric anomalies and the ENSO is discussed.

This paper is organized as follows. Dataset used in this study are described in the next section. In section 3 , a statistical analysis is performed and some characteristic features and time evolution of the zonally asymmetric anomalies over the Indian Ocean are presented. Section 4 describes the onset processes and precursory signals of the zonally asymmetric anomalies. A dynamical link between intensification of the local Hadley circulation over the western Pacific, and the onset of the zonally asymmetric anomalies in section 5 are indicated. The possible modulating process of the local Hadley circulation, and its seasonality will be discussed in section 6 . The last section presents the summary.

\section{Dataset for analysis}

The principal datasets in this study are monthly mean OLR data derived from the NOAA satellite. The data are on $2.5^{\circ} \times 2.5^{\circ}$ 
grid and cover the period from June 1974 to 1999 with a gap from March to December 1978. Low OLR values indicate deep convection and pronounced condensational heating over tropical and subtropical regions (Liebmann and Smith 1996). The monthly mean SST data from 1982 to 1999 is obtained by the reanalysis optimal interpolation scheme produced by the NCEP of NOAA. This reanalysis produces daily and weekly values with $1^{\circ} \times 1^{\circ}$ spatial resolution, and using in situ SST data from ships, buoys and bias-corrected satellite SST data (Reynolds and Smith 1994). The atmospheric circulation data fields in this study are adopted from the products of the NCEP/NCAR reanalysis project (Kalnay et al. 1996). The monthly mean horizontal and vertical wind data between $100 \mathrm{hPa}$ and $1000 \mathrm{hPa}$ pressure level for the period 1949-1998 are used. OLR anomalies and circulation anomalies are generated by removing the climatological monthly means computed for 1974-1998. Monthly SST anomalies are based on the climatological monthly mean annual of 1982-1998 from Reynolds SST data.

\section{Evolution of the zonally asymmetric anomalies}

An EOF analysis of monthly mean OLR anomalies over the Indian Ocean $\left(20^{\circ} \mathrm{S}-30^{\circ} \mathrm{N}\right.$, $30^{\circ} \mathrm{E}-120^{\circ} \mathrm{E}$ ) is performed to clarify the dominant features of the interannual variability of tropical convection. In advance, a liner trend is removed from the original data, and used 3 -months running mean values to omit shortterm fluctuations such as intraseasonal variations. The spatial pattern of the first mode $(18.2 \%)$ represents a zonally asymmetric pattern between the eastern and western Indian Ocean as shown in Fig. 2. Taking a close look at its score series, it turns out that this pattern is characterized as an intermittent phenomenon rather than a periodic one, and its negative values are noticeable from boreal summer to winter in 1982, 1994 and 1997. These three years correspond to the occurrence year of the SST dipole mode (Saji et al. 1999). Therefore, the zonally asymmetric anomalies of convection correspond well to the SST anomalies field. Next, the EOF analysis to each seasonal mean OLR data is applied. Figure $3 a-d$ show the spatial pattern and score series of the first mode in four seasons respectively. The zonally

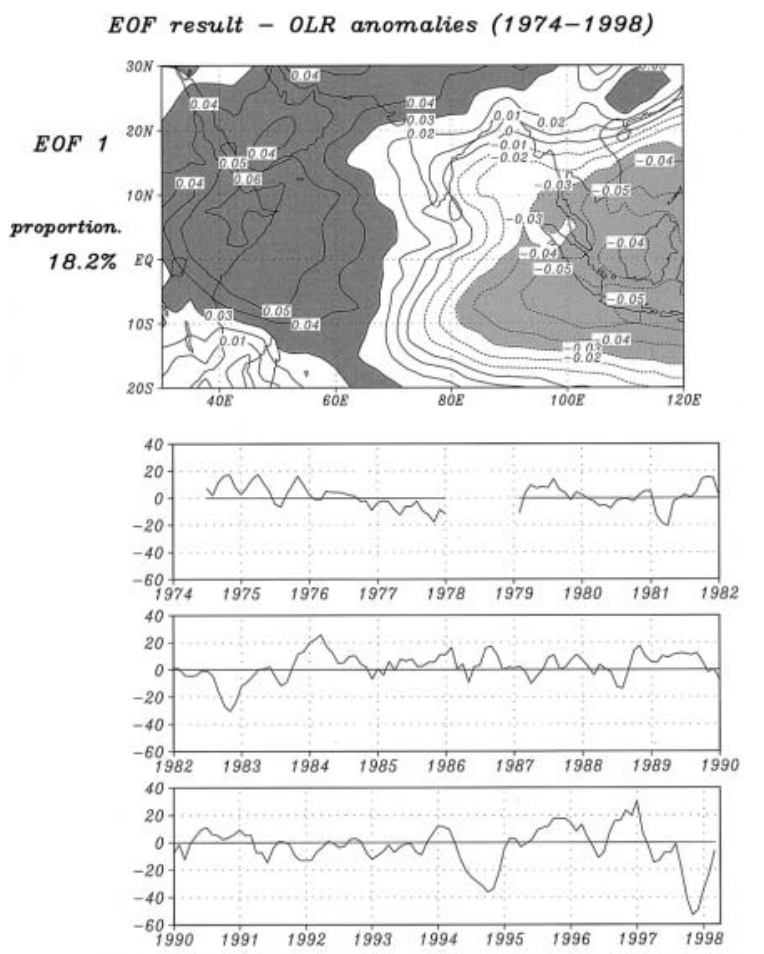

Fig. 2. Spatial pattern and time series of the first mode deduced by EOF analysis to the monthly mean OLR anomalies. Contours are drawn in relative units. Light and heavy shading indicates regions with marked positive and negative, respectively Labels of $\mathrm{x}$-axis indicate January in each year.

asymmetric pattern is prominent both in boreal autumn (Fig. 3d) and winter (Fig. 3a). However, this pattern indicated from the EOF analysis of using monthly series as shown in Fig. 2 is distinguished only in boreal autumn (Fig. 3d), considering the regression coefficients and the score series. In other seasons, different spatial structure of interannual variability is obtained (Fig. 3b-c). For instance, most dominant pattern of OLR anomalies in boreal spring (Fig. 3b) shows an equatorially asymmetric structure as indicated by Kawamura (1998). Therefore, the zonally asymmetric pattern of convection is prominent in boreal autumn, and not clear in other seasons.

In order to describe the evolution of the zonally asymmetric anomalies, the composite diagram of the longitude-time section of OLR, $850 \mathrm{hPa}$ wind and SST anomalies along lat- 

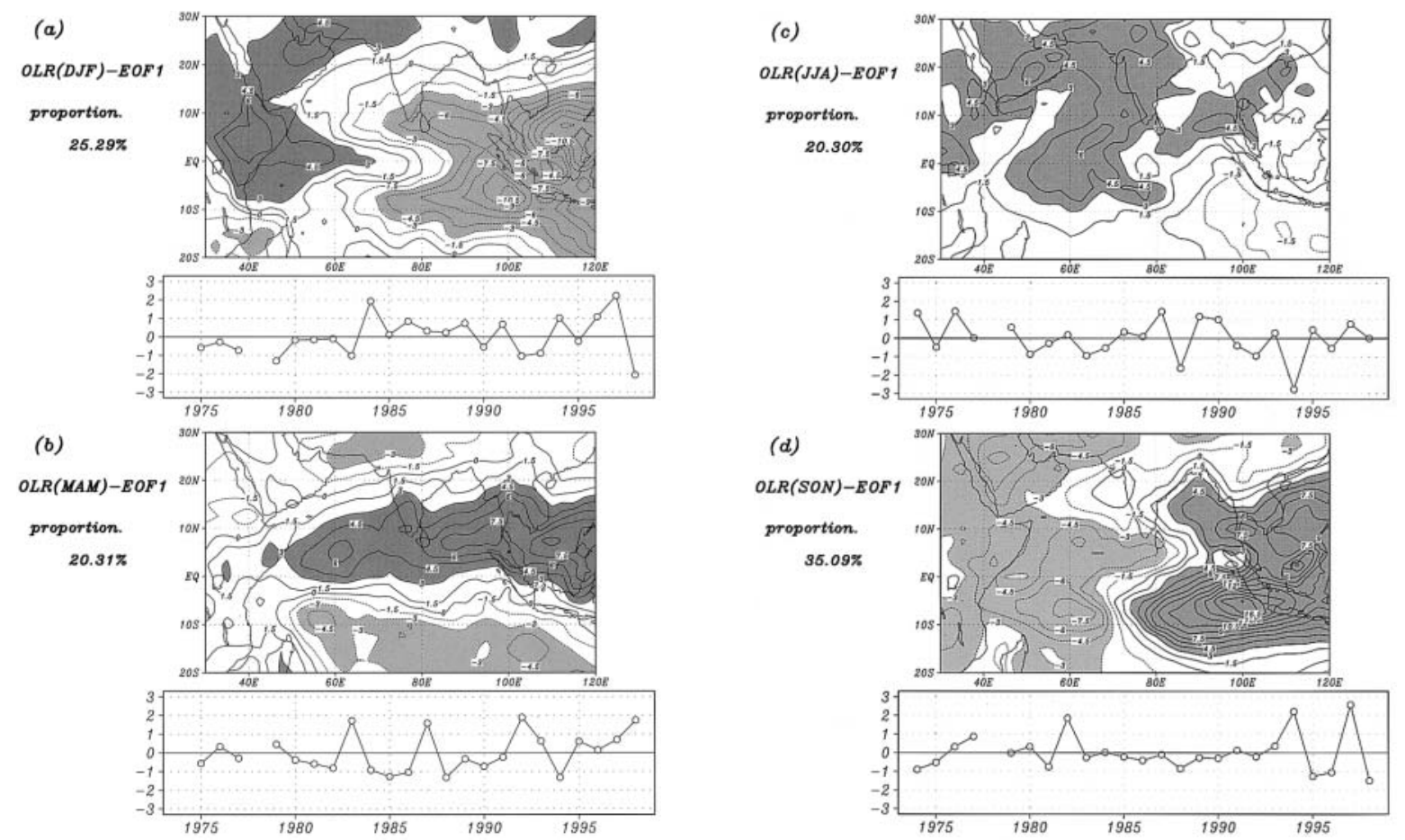

Fig. 3. Normarized time series of the first mode deduced by EOF analysis to the seasonal mean OLR anomalies and regression coefficients between this series and seasonal mean OLR. (a) DJF, (b) MAM, (c) JJA, (d) SON. Contours are drawn in relative units. Light and heavy shading indicates regions with marked positive and negative, respectively.

itudinal band between $10^{\circ} \mathrm{S}$ and the equator is presented for 1982, 1994 and 1997 in Fig. 4. The vertical axis of this figure cover the period from January in based year to October in next year. Since July in based year, the remarkable cool SST anomalies were observed over the southeastern Indian Ocean, especially along the west coast of Sumatra (the vicinity of $100^{\circ} \mathrm{E}$ ), and OLR anomalies over that region became positive, indicating suppressed convection. The warm SST anomalies over the midwestern Pacific were also prominent from the same month. By contrast, the negative OLR anomalies over the mid-western Indian Ocean were observed with several months lag to the eastern anomalies, showing enhanced convection associated with increased SST anomalies. These anomalies of OLR and SST developed from boreal summer to autumn. The easterly wind anomaly at $850 \mathrm{hPa}$ prevailed over the mid Indian Ocean between the positive and negative OLR anomalies during boreal au- tumn. These zonally asymmetric anomalies, and the easterly wind anomaly decayed in boreal winter. In this way, the zonally asymmetric anomalies over the Indian Ocean appeared at first in boreal summer, and developed toward to boreal autumn. In addition, the large positive SST anomalies whole over the Indian Ocean from boreal winter to spring in next year might correspond to the broad-scale warming pattern connected with the ENSO (Villwock and Latif 1994; Tourre and White 1995).

Some recent studies have noted that these SST anomalies over the Indian Ocean are generated by the dynamic response of the ocean to wind anomalies. Vinayachandran et al. (1999) showed that SST anomalies over the Indian Ocean, in the case of 1994, could be produced by the weakening of the eastward equatorial jet, in the ocean general circulation model experiment forced by interannual winds. They indicated that the strong easterly wind anomaly consequent to weakening the Walker 
(a) OLR and 850hPa Wind anomalies

(b) SST anomalies
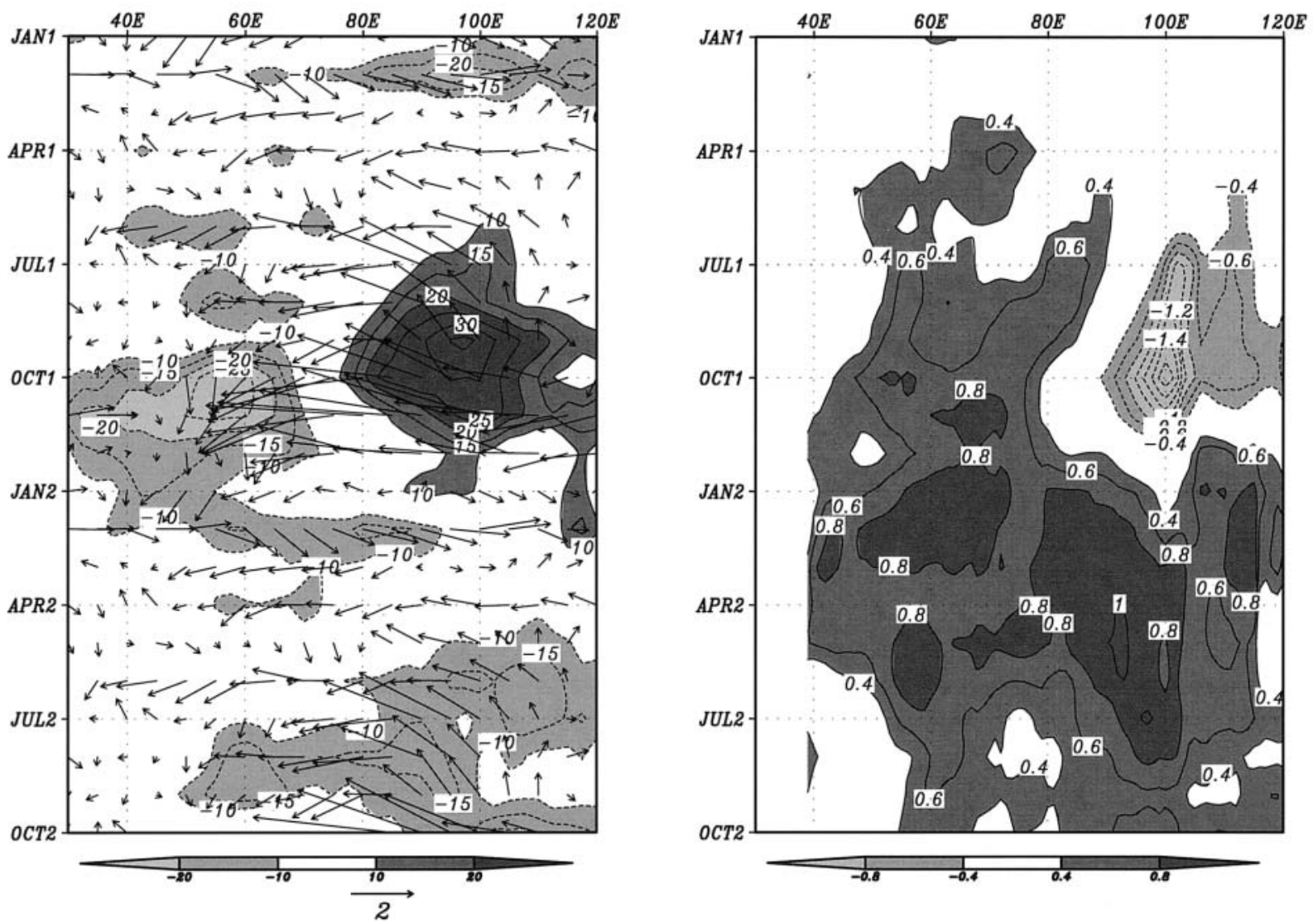

Fig. 4. (a) Composite diagram of time-longitude sections of OLR and $850 \mathrm{hPa}$ wind anomalies averaged between $10^{\circ} \mathrm{S}$ and equator for 1982,1994 and 1997 . Contour interval is $10 \mathrm{~W} / \mathrm{m}^{2}$ and unit is $2 \mathrm{~m} / \mathrm{s}$. (b) As in (a) but for SST anomalies. Contour interval is $0.2^{\circ} \mathrm{C}$.

circulation over the Indian Ocean reduced warm water build-up, and produced negative SST anomalies in the eastern Indian Ocean, whereas this wind anomaly generated oceanic heat advection of warm water to the midwestern Indian Ocean, and changed SST anomalies to a positive sign. Webster et al. (1999) also explained the dynamic response of the ocean downwelling Rossby wave, derived by the anomalous wind. It causes the Ekman ridge to propagate westward and deepens thermocline associated with reducing upwelling over the western Indian Ocean. These negative SST anomalies associated with anomalous wind naturally suppressed convection over the southeastern Indian Ocean, and positive SST anomalies conversely enhanced the convection over the mid-western Indian Ocean. The lowlevel divergence of moist air over the eastern region also led to anomalous moisture transport that enhanced convection over the midwestern Indian Ocean. These positive feedback between enhanced and suppressed convection regions through the surface zonal wind anomalies, helped to maintain and intensify the zonally asymmetric anomalies. In this manner, it is clear that this zonally asymmetric anomalies are developed as a result of the atmosphereocean coupling, and are self-maintained from boreal summer to winter (Behera et al. 1999; Saji et al. 1999; Webster et al. 1999). Thus, the conjecture can be that this phenomenon could be developed and maintained by itself, once anomalous wind arises from some reason. 


\section{Onset of the zonally asymmetric anomalies}

The zonally asymmetric anomalies are manifestations of a self-maintaining phenomenon through the atmosphere-ocean interaction in the previous section. A triggering mechanism, or precursory signal of these anomalies, has already been discussed by some studies (Webster et al. 1999; Saji et al. 1999; Ueda and Matsumoto 2000), but yet it is not clear, as mentioned in the introduction. Hence, the re-focus on this triggering phase when both negative SST anomalies, and positive OLR anomalies first appeared over the eastern Indian Ocean in June-July (Fig. 4).

To find notable precursory signals by comparing the atmospheric and oceanic conditions in June with those in July, the spatial patterns of OLR and SST anomalies in June (Left) and July (Right) in 1982, 1994 and 1997 are presented, respectively as shown in Fig. 5-7. Also exhibited are $200 \mathrm{hPa}, 850 \mathrm{hPa}$ and $1000 \mathrm{hPa}$ wind anomalies. The OLR, SST and wind anomalies over the eastern Indian Ocean were not evident during June in 1982 (Fig. 5, Left). The SST anomalies over the maritime continent showed the negative. Meanwhile, in July, OLR over the maritime continent indicated large positive anomalies, and SST showed marked negative anomalies off the Sumatra coast (Fig. 5, Right). As for low-level wind filed, southeasterly wind anomaly was intensified over the southeastern Indian Ocean and westerly wind anomaly occurred over the south Asia, and western north Pacific. These crossequatorial wind anomalies accelerated the climatological southeasterly off the Sumatra coast (see Fig. 1c). Considering that the upper-level wind anomaly was northeasterly over the maritime continent, it is suggested that the meridional circulation over the western Pacific was considerably strengthened. This meridional circulation is called the "local Hadley circulation over the western Pacific" hereafter. Figure 8 shows the vertical-latitude section of horizontal wind, and vertical wind anomalies over the western Pacific and maritime continent $\left(90^{\circ} \mathrm{E}-\right.$ $120^{\circ} \mathrm{E}$ ) in June (Left) and July (Right) to clarify the intensification of this local Hadley circulation. The low-level southerly, and upper-level northerly wind anomalies, were clearly in- tensified from June to July in 1982, (Fig. 8, Top).

The case in 1994 shows the remarkable meridional circulation anomalies. The OLR and SST anomalies over the eastern Indian Ocean were not clear, and upper-level wind anomaly was easterly about the whole of the Indian Ocean during June in 1994 (Fig. 6, Left). However, in July, OLR over the eastern Indian Ocean indicated large positive anomalies, and remarkable negative SST anomalies appeared off the Sumatra coast (Fig. 6, Right). It is also interesting to note that convective activity over the South China Sea and the Philippine Sea (hereafter referred as SCS/PS) was more enhanced than usual. These convection anomalies were extremely large. In this manner, the meridionally asymmetric convection anomalies were clearly seen between the SCS/PS, and the south of maritime continent. Associated with this meridionally asymmetric convection anomalies, a southeasterly wind anomaly over the southeastern Indian Ocean, and westerly wind anomaly over the western north Pacific prevailed. It is also obvious that the local Hadley circulation over the western Pacific was considerably strengthened from June to July in 1994. (Fig. 8, Middle).

On the other hands, OLR and SST anomalies during June in 1997 (Fig. 7, Left) were different from those in 1982 and 1994. Remarkable differences were positive OLR anomalies over most of the area to the east of $80^{\circ} \mathrm{E}$, westerly anomaly at $200 \mathrm{hPa}$ wind field and strong easterly anomaly at $850 \mathrm{hPa}$ wind field over the mid-western Indian Ocean. However, positive OLR anomalies over the southeastern Indian Ocean, and negative OLR anomalies over the SCS/PS, were seen in July (Fig. 7, Right) suggesting that the local Hadley circulation over the western Pacific was strengthened. The negative SST anomalies along the west coast of the Sumatra, and lower $(850 \mathrm{hPa}$ and $1000 \mathrm{hPa}$ ) southeasterly wind anomaly off that coast first appeared in July, in the same manner as the case of 1994. According to the vertical structure that ascending flow over the SCS/ PS arose from active convection anomalies and upper-level northerly anomaly was accelerated during July (Fig. 8, bottom), it is also evident that the local Hadley circulation over the western Pacific was intensified in July 1997. 

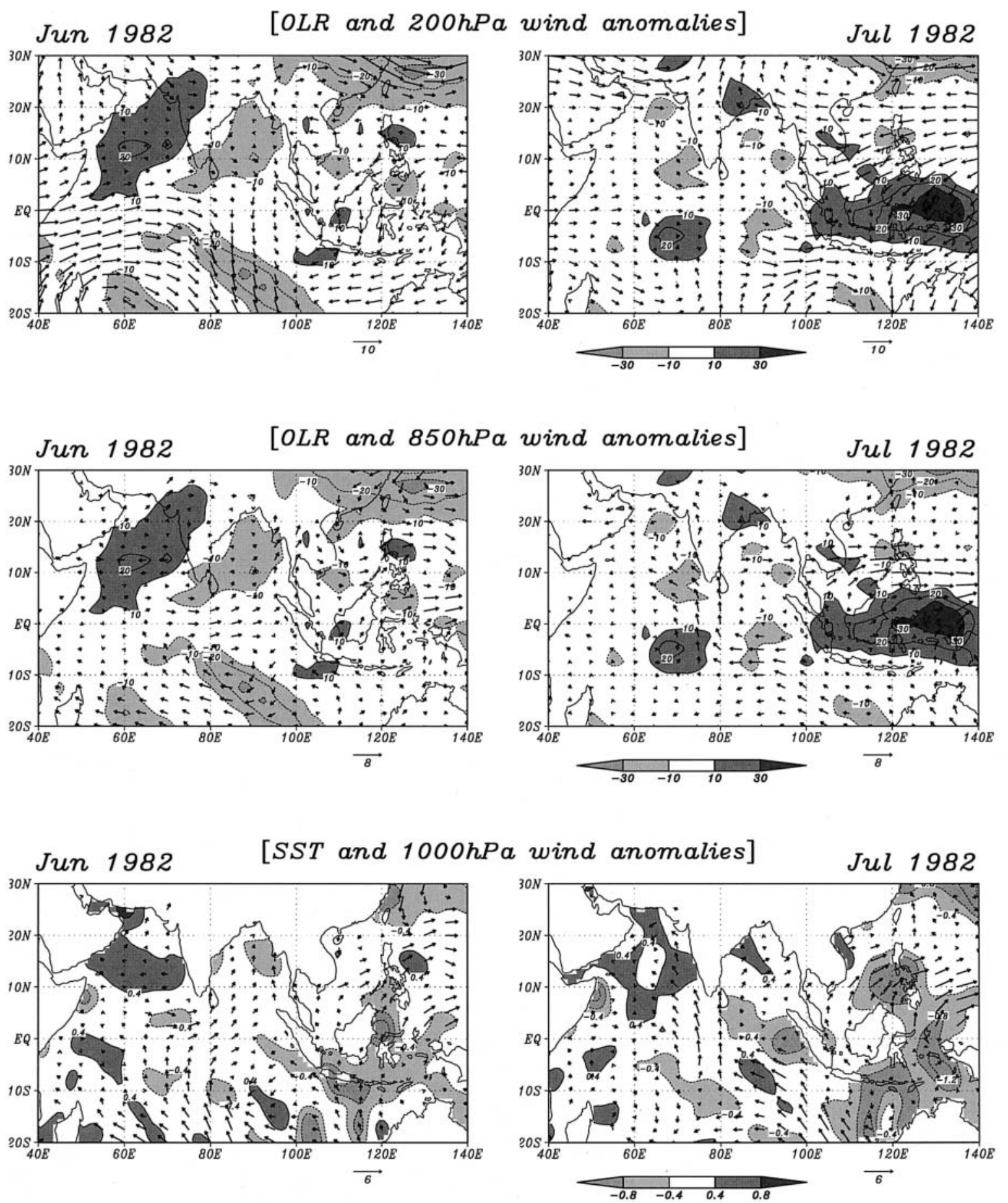

Fig. 5. (Top) Spatial patterns of OLR and $200 \mathrm{hPa}$ wind anomalies in each month (Left: June in 1982, Right: July in 1982). Contour interval is 10 and unit is $10 \mathrm{~m} / \mathrm{s}$. (Middle) As in (Top) but for OLR and $850 \mathrm{hPa}$ wind anomalies. Unit is $8 \mathrm{~m} / \mathrm{s}$. (Bottom) As in (Top) but for SST and $1000 \mathrm{hPa}$ wind anomalies. Contour interval is $0.4^{\circ} \mathrm{C}$ and unit is $6 \mathrm{~m} / \mathrm{s}$. 

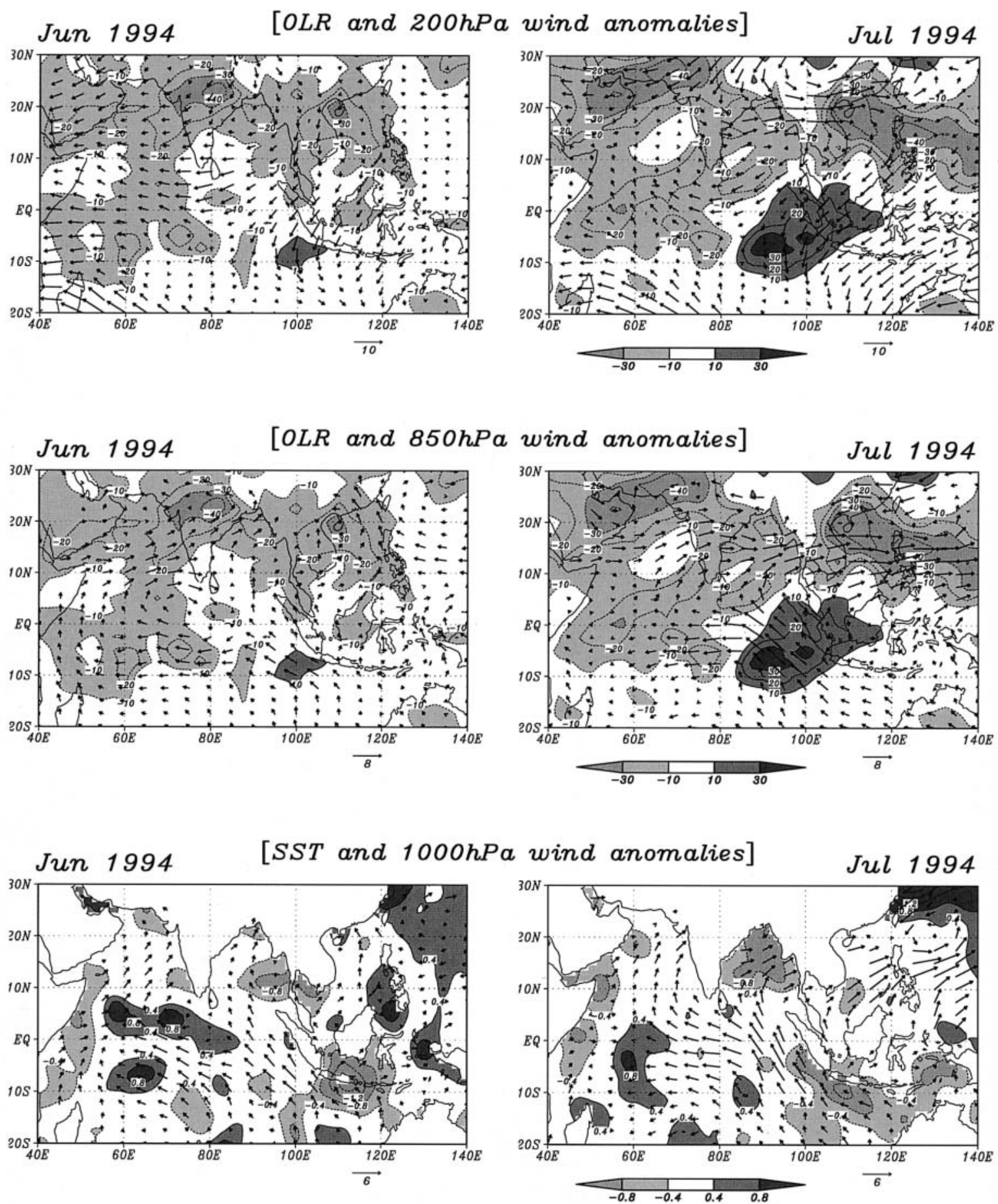

Fig. 6. As in Fig. 5 but for 1994.

From the comparison between atmospheric and oceanic condition in June and those in July, it is strongly suggested that the southeasterly wind acceleration over the southeast- ern Indian Ocean in July, associated with the meridionally asymmetric convection anomalies over the western Pacific, could be one of the precursory signals of the zonally asymmetric 
Jun 1997

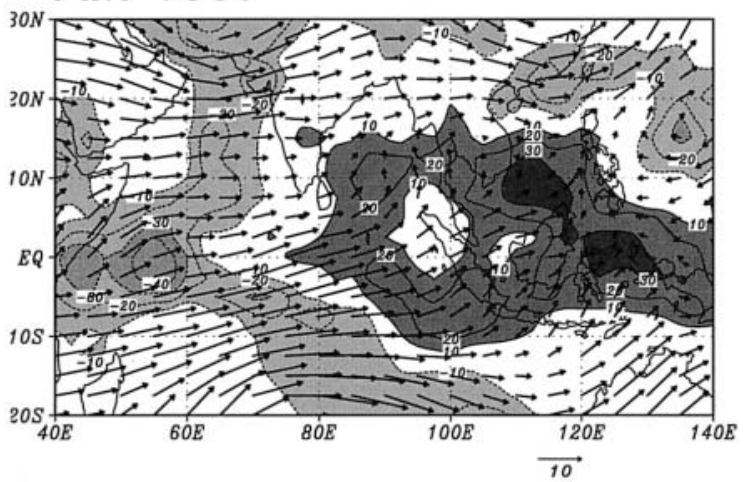

[OLR and 200hPa wind anomalies]

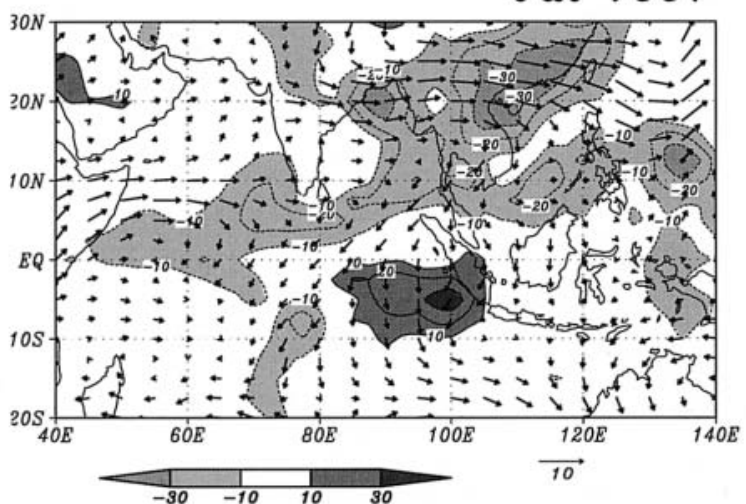

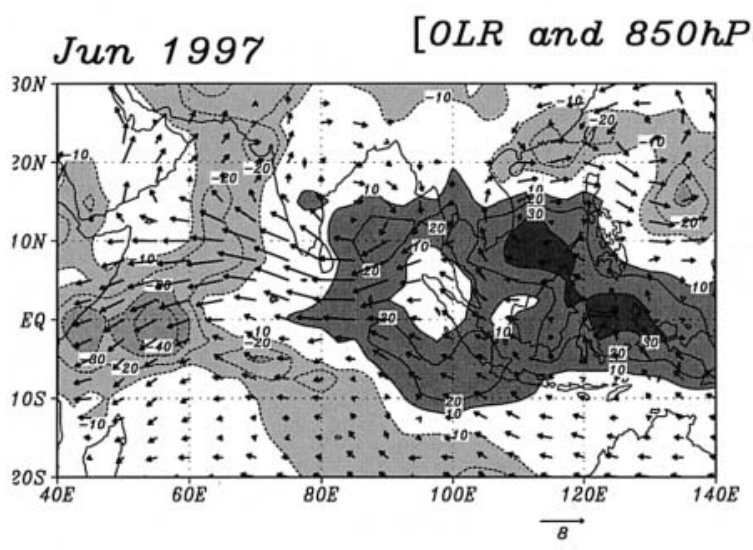
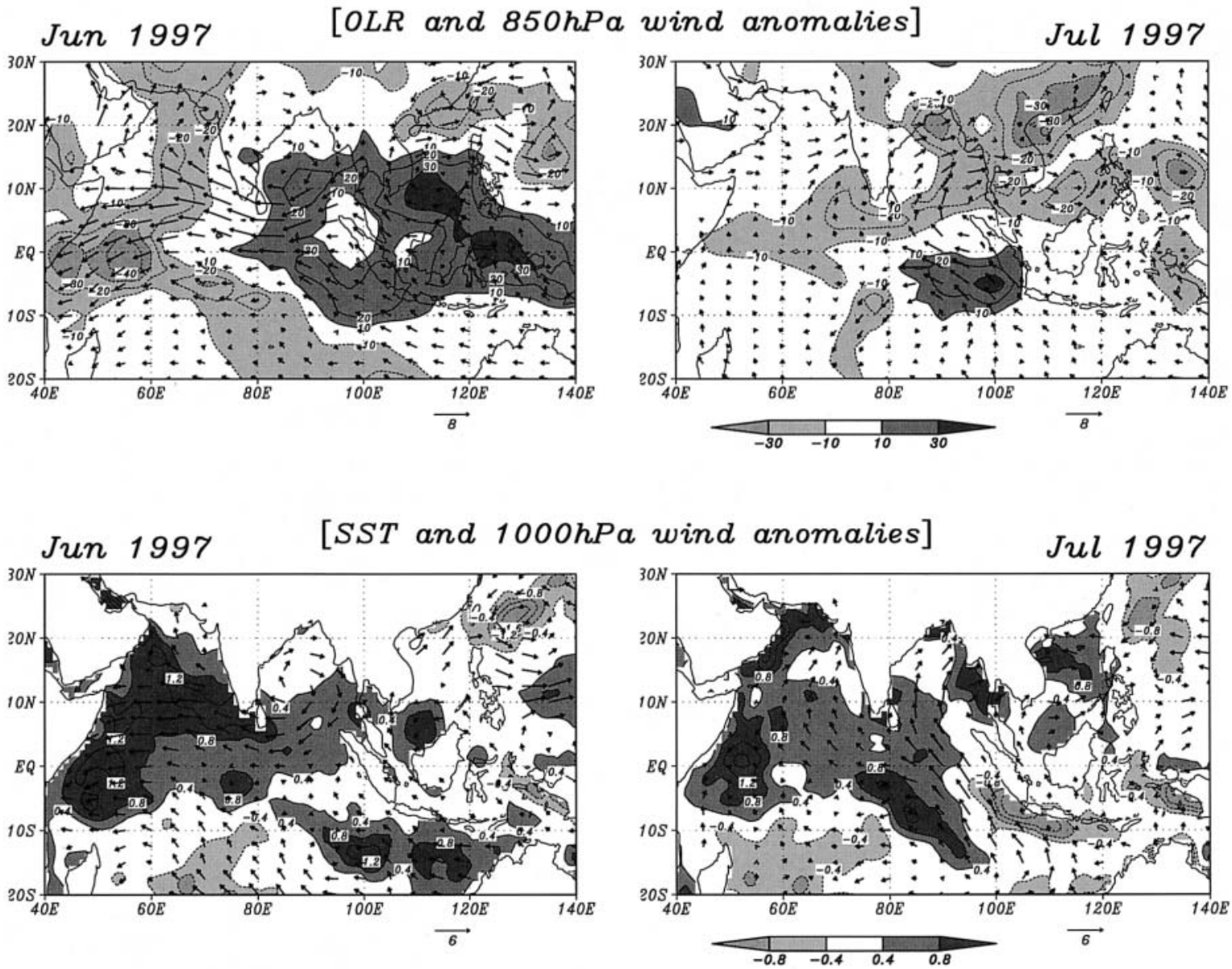

Fig. 7. As in Fig. 5 but for 1997.

anomalies in the following autumn. Actually, Behera et al. (1999) indicated that both entrainment cooling, and evaporative cooling associated with southeasterly wind anomaly, pro- duced negative SST anomalies off the coast of the Sumatra in the case of 1994. Furthermore, it is well known that climatological mean thermocline depth off the coast of Sumatra rapidly 
Jun 1982

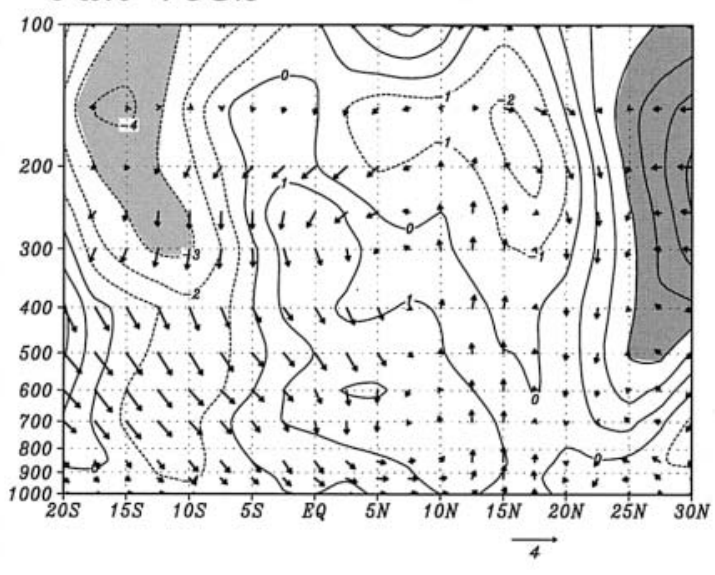

Jun 1994

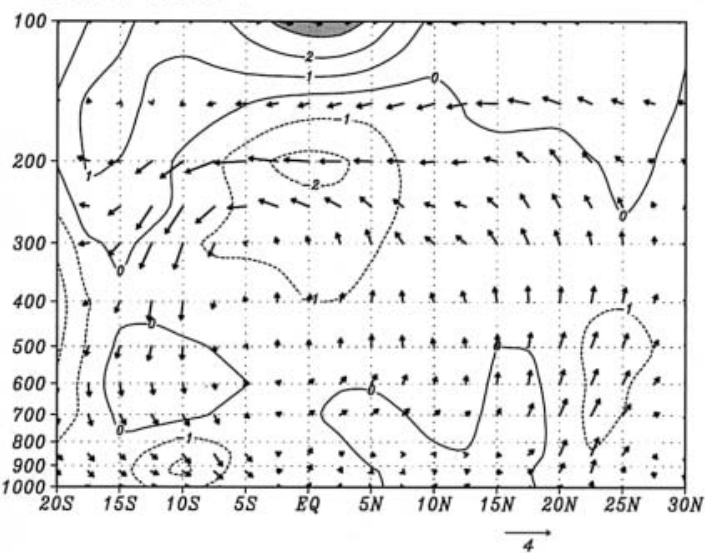

Jun 1997

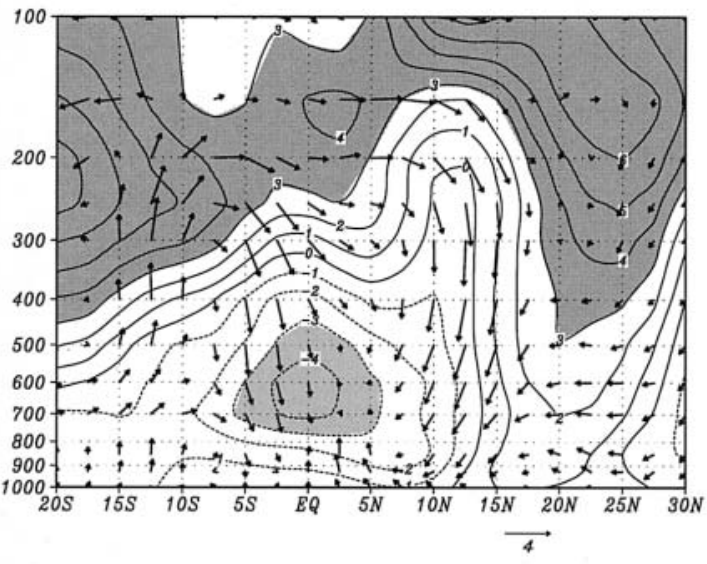

Jul 1982

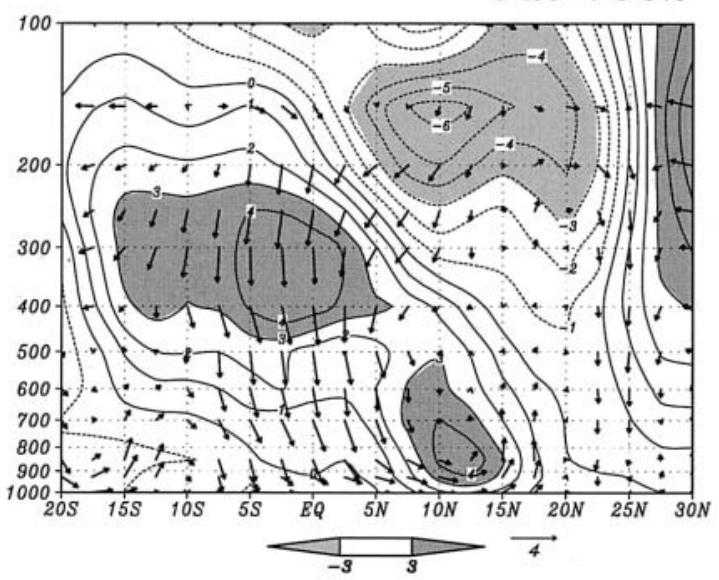

Jul 1994

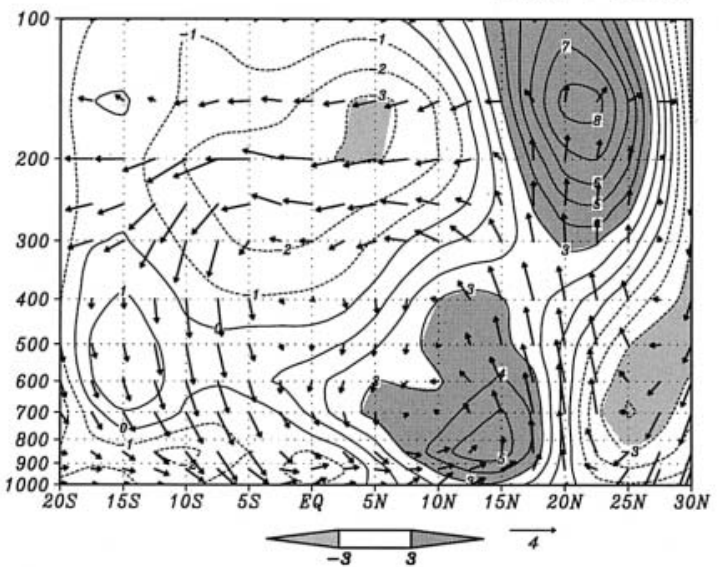

Jul 1997

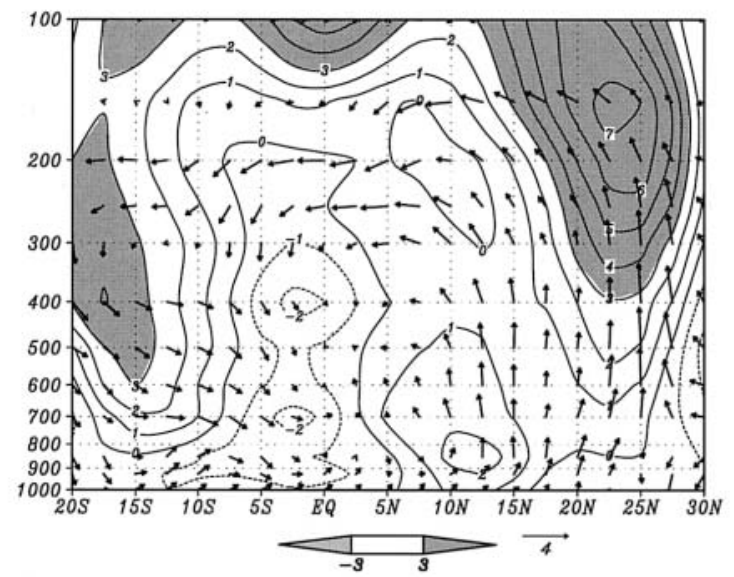

Fig. 8. Latitude-height section of meridonal and vertical wind anomalies along between $90^{\circ} \mathrm{E}-120^{\circ} \mathrm{E}$ in each month (Left: June, Right: July) in 1982, 1994 and 1997. Unit for the meridional wind is $4 \mathrm{~m} / \mathrm{s}$, while the vertical wind is $10^{2} \mathrm{~Pa} / \mathrm{s}$. Contour and shading are zonal wind anomaly along the same region. 
is shallowed from June to July, while that off Africa is deepened, and the zonal slope of the thermocline appears to be the mirror image of the slope of the sea surface (Tomczak and Godfrey 1994). Thus, climatological southeasterly wind in July provides a favorable condition for cool climatological SST during a year, and enhancemental southeasterly wind provide more SST cooling over the southeastern Indian Ocean.

In order to understand the interannual variability of the southeasterly wind acceleration over the southeastern Indian Ocean, the near surface $(1000 \mathrm{hPa})$ zonal wind, meridional wind and wind speed anomalies area-averaging $90^{\circ} \mathrm{E}-100^{\circ} \mathrm{E}$ and $10^{\circ} \mathrm{S}$-equator are examined. Figure 9 shows time series of these components in July during the period from 1949 to 1998 . The sign of wind anomalies and the positive wind speed anomaly in 1982, 1994 and 1997 implies enhancement of southeasterly component over this region. In the case of other zonally asymmetric anomalies mentioned by Saji et al. (1999), wind anomaly in July also appeared in the southeasterly in 1961, 1967 and 1972. However, the southeasterly wind acceleration in Fig. 9 are shown not only in the six years following the zonally asymmetric anomalies over the Indian Ocean, but also in other
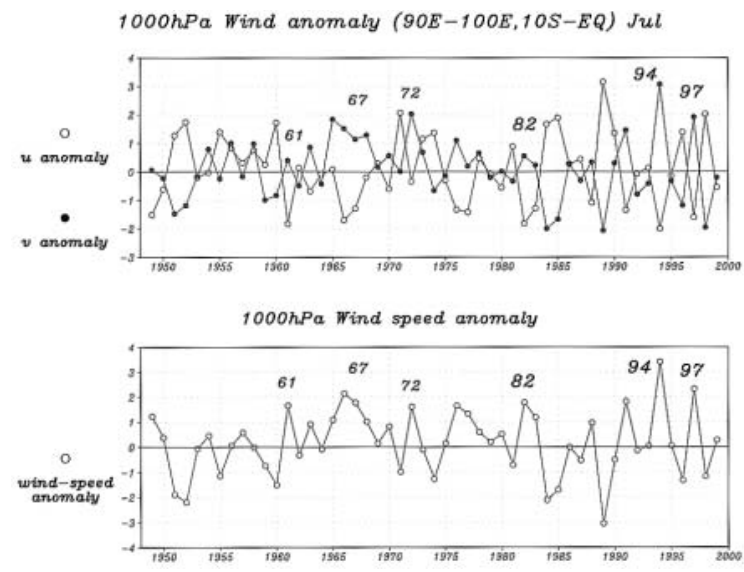

Fig. 9. (Top) Time series of the zonal and meridional wind anomalies $(\mathrm{m} / \mathrm{s})$ in box-averaged between $90^{\circ} \mathrm{E}-100^{\circ} \mathrm{E}$ and $10^{\circ}$ S-equator. (Bottom) Time series of the wind speed anomalies $(\mathrm{m} / \mathrm{s})$ in boxaveraged same as (Top). years (1966, 1976, 1991 and so on). Thus, the southeasterly wind acceleration in July over the southeastern Indian Ocean could be a necessary condition for the zonally asymmetric pattern in next autumn, rather than the sufficient condition is emphasized. In addition, these interannual variability of the southeasterly wind acceleration appeared in the time series (same as Fig. 9) in August, but never in June (not shown). Therefore, the importance of this southeasterly wind acceleration in July is emphasized, as one of the dominant precursory signals of the zonally asymmetric anomalies.

\section{The linkage between the local Hadley circulation and the zonally asymmetric anomalies}

In the previous section, the importance of the southeasterly wind acceleration over the southeastern Indian Ocean is pointed out. The question of what produces these wind anomalies is raised here. In generally, with a positive heat source in the north, and a negative heat source in the south across the equator, the circulation is toward the north between heat sources. This meridionally circulation is also present to the west of the forcing and increases when the separation between the anomalies increases (Gill 1980, Fig. 3). Hence, the southeasterly wind anomaly is closely linked to the meridionally asymmetric convection anomalies over the western Pacific is suggested. In other words, enhanced convection over the northern part, and suppressed convection over the southern part, intensify the local Hadley circulation over the western Pacific in boreal summer (refer to Fig. 1c).

To facilitate further inspection of intensification of the local Hadley circulation, the EOF analysis of OLR anomalies over the region $\left(15^{\circ} \mathrm{S}-25^{\circ} \mathrm{N}, 90^{\circ} \mathrm{E}-130^{\circ} \mathrm{E}\right)$ is performed, which covered from the SCS/PS to the maritime continent only in July, in reference to Fig. 6 and Fig. 7. Figure 10 shows a spatial pattern and their time series for the first mode. The spatial structure of the first mode $(23.9 \%)$ indicates a meridionally asymmetric pattern between the SCS/PS, and the maritime continent. Convection over the SCS/PS (the maritime continent) is enhanced (suppressed) in 1976, 1977, 1982, 1987, 1991, 1994 and 1997. It is found that the time series of this first mode coincide well with 

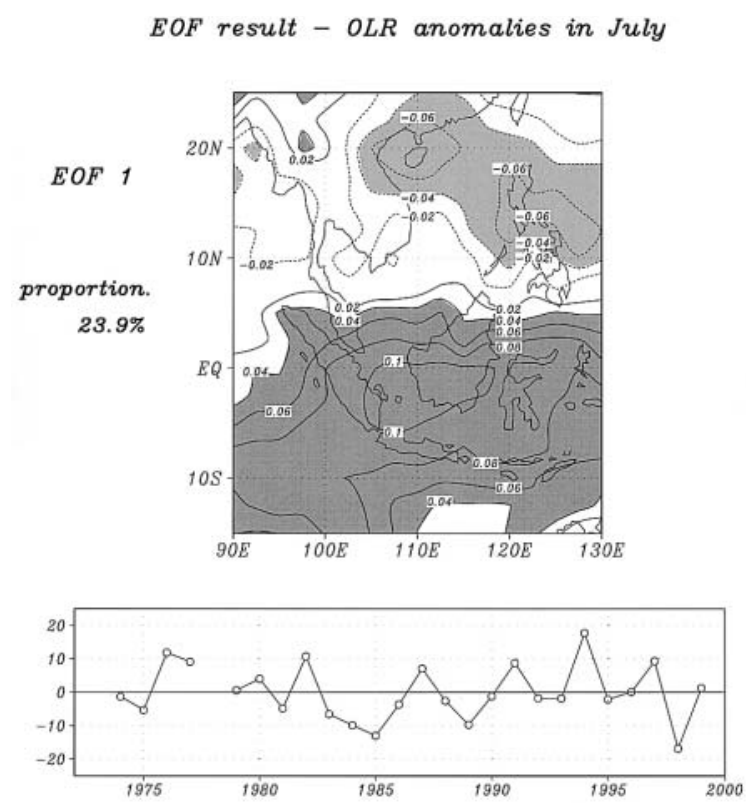

Fig. 10. Spatial pattern and time series of the first mode deduced by EOF analysis to the OLR anomalies over the maritime continent and the South China Sea in only July. Contour and shading is same as Fig. 2.

the southeasterly wind acceleration over the south-eastern Indian Ocean (Fig. 9) with a high correlation (0.69). Thus, the interannual variability of the southeasterly wind anomaly in July is confirmed to be closely linked to the meridionally asymmetric anomalies of convection between the SCS/PS and the maritime continent.

In order to describe the evolution of the zonally asymmetric anomalies over the Indian Ocean associated with the meridionally asymmetric convection anomalies over the western Pacific, the lagged regression of the OLR, SST and wind field at $850 \mathrm{hPa}$ and $1000 \mathrm{hPa}$ is calculated based on the time series of first mode (see Fig. 10). The evolution covers the period from month 0 (July) to month +3 (October) as shown in Fig. 11. In month 0 (July), a region of negative OLR anomalies are found located over the SCS/PS, while positive OLR anomalies are located over the south of the maritime continent. The southeasterly wind anomaly off the Sumatra coast and westerly wind anomaly over the southeast Asia indicate the intensification of the local Hadley circulation over the western Pacific. The negative SST anomalies are also found off the Sumatra coast. In the next month (August), the negative OLR anomalies located over the SCS/PS turn to the positive, but OLR and SST off Sumatra persist in the anomalous condition in the previous month (July). The westerly wind anomaly over southeast Asia is inconspicuous, and the positive SST anomalies also appear in the mid-Indian Ocean. These positive SST anomalies grow up to the whole of west side of the Indian Ocean associated with the easterly wind anomaly in the following month. In month +2 (September) and +3 (October), SST anomalies over the western Indian Ocean develop to large positive and that over the eastern Indian Ocean persist in the negative. OLR anomalies over the Indian Ocean also indicate the zonally asymmetric pattern, and low-level wind anomaly in the mid-Indian Ocean, shows strong easterly.

Moreover, the significant anomalies of OLR, SST and wind field in June lagged -1 (not shown) are not found. Thus, July has been proved to be the onset phase of the zonally asymmetric anomalies prevailing late summer through autumn, when the SST anomalies over the mid-eastern Indian Ocean are closely related to the convection anomalies over the maritime continent, presumably through the cross equatorial flow (the southeasterly wind acceleration). Then, in some extreme cases of this mode in July 1982, 1994 and 1997, the zonally asymmetric anomalies developed over the whole Indian Ocean in autumn through the atmosphere-sea interaction. Though there is open questions why the zonally asymmetric anomalies developed in this three years alone, it will be discussed in the next section.

\section{Discussion}

The intensification of the local Hadley circulation over the western Pacific in July is the clear precursory signal of the zonally asymmetric anomalies over the Indian Ocean in the following autumn. However, some questions still remain. One is why in some years the zonally asymmetric anomalies did not develop during boreal autumn as 1976, 1987 and 1991, though the meridionally asymmetric pattern was found from EOF analysis result (see Fig. 10). In order to clarify this problem, the time series of 
OLR and $850 h P a$ wind
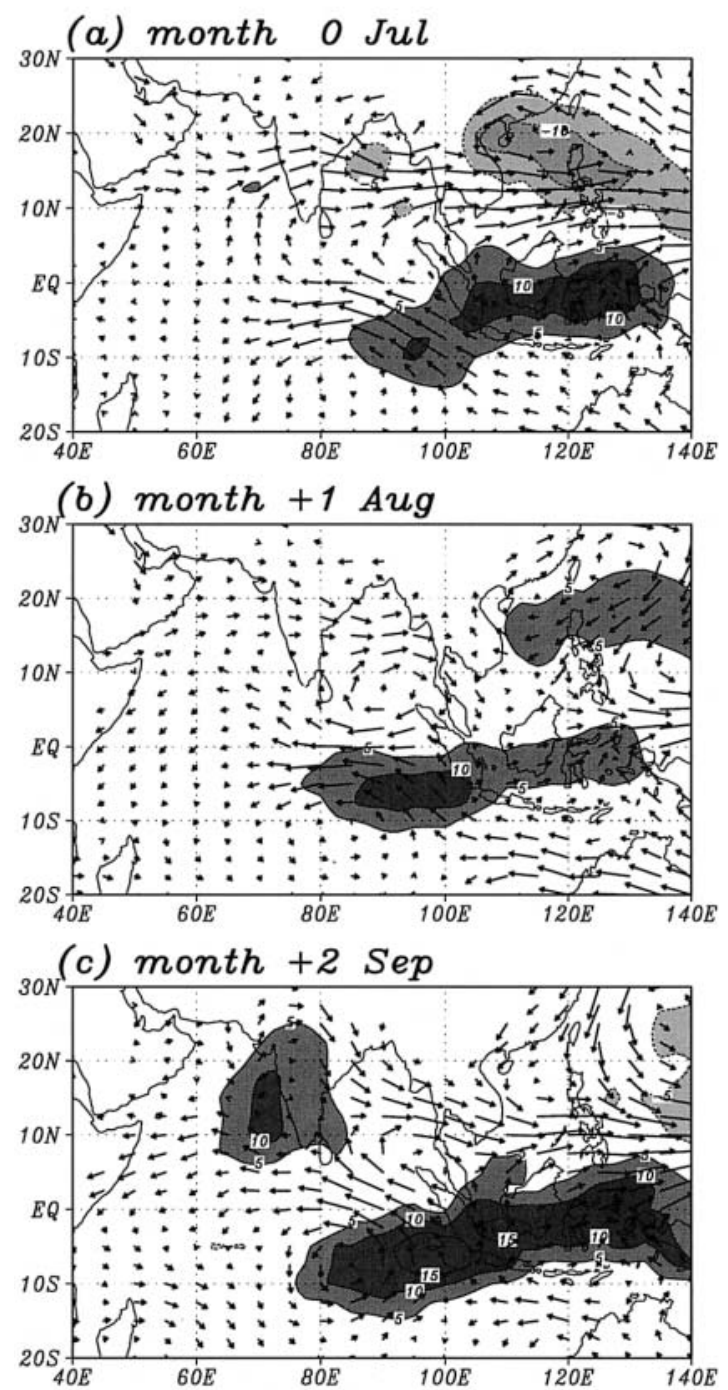

(d) month +3 oct

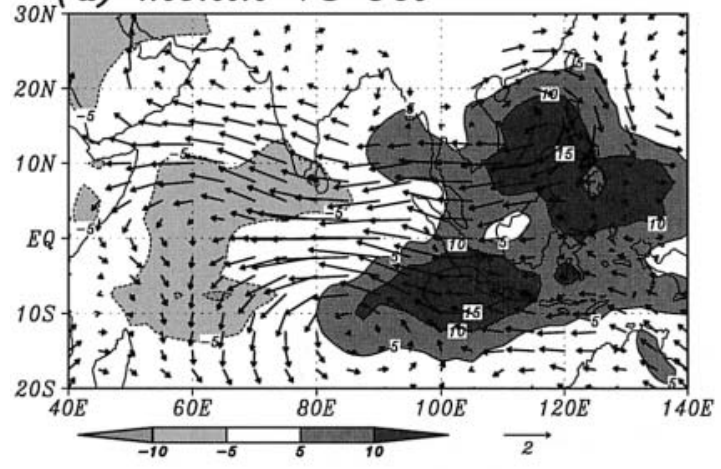

SST and $1000 \mathrm{hPa}$ wind
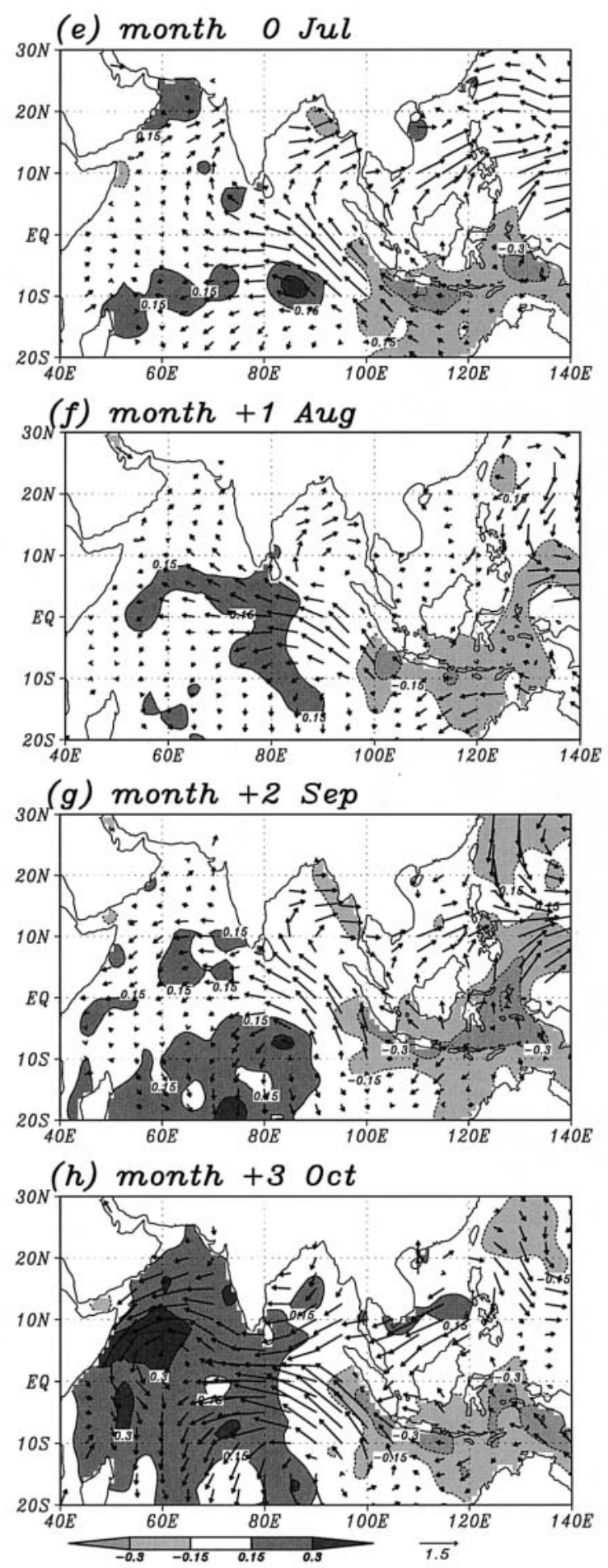

Fig. 11. Lagged regression coefficients between the time series of first mode (see Fig. 10) and OLR, $850 \mathrm{hPa}$ winds, at (a) month 0 (July), (b) month +1 (August), (c) month +2 (September), (d) month +3 (October). Contour interval is $2 \mathrm{~W} / \mathrm{m}^{2}$, and length of the reference arrow is equivalent $2 \mathrm{~m} / \mathrm{s}$. (e)-(h) is same as (a)-(d) but for SST and $1000 \mathrm{hPa}$ winds. Contour interval is $0.15^{\circ} \mathrm{C}$ and length of the reference arrow is equivalent $1.5 \mathrm{~m} / \mathrm{s}$. 


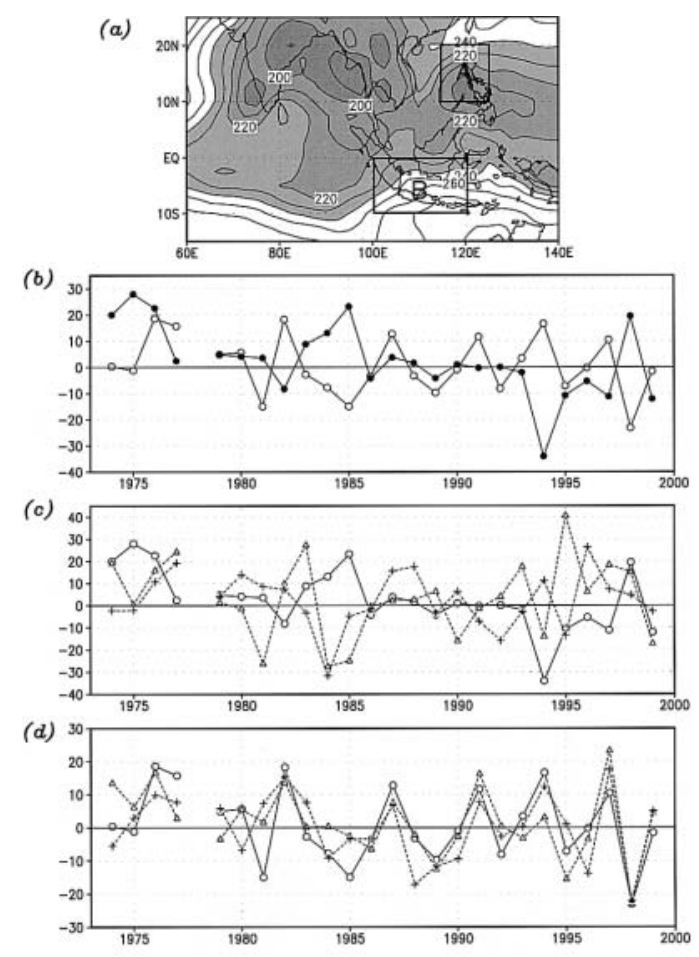

Fig. 12. (a) climatological OLR JJA mean field, (b) Time series of OLR anomalies in July. Closed circle shows anomalies of area-averaging over the region $\mathrm{A}$. Open circle shows region B. (c) Time series of OLR anomalies in region $\mathrm{A}$. Open circle shows anomalies in July. Triangle shows in June and cross shows in August. (d) same as (c) but for region $\mathrm{B}$.

OLR anomalies over the SCS/PS (closed circle in Fig. 12b) and the maritime continent (open circle in Fig. 12b) in July is examined. This time series over the SCS/PS shows indeterminate interannual variability, while that over the maritime continent shows a periodical one. The OLR anomalies over the SCS/PS was not always correlated to that over the maritime continent. Hence, Figure 12 indicates that the intensification of the local Hadley circulation over the western Pacific prevailed in 1982, 1994 and 1997 alone. In 1976, 1987 and 1991, the convection over the maritime continent was suppressed but that over the SCS/PS was not enhanced, and thereby, the local Hadley circulation over the western Pacific was probably not intensified. In fact, the significant wind anomalies over the SCS/PS and the maritime continent were not found in these years, though the strong anticyclonic (cyclonic) wind anomalies at low-level prevailed over the Indian Ocean in 1976 and 1991 (1987). Consequently, the negative SST anomalies off the Sumatra coast, and the remarkable zonally asymmetric anomalies over the Indian Ocean were not shown. This suggests the importance of the meridionally asymmetric pattern of convection anomalies over the western Pacific, that is, the importance of convection anomalies both over the SCS/PS, and the maritime continent in July.

Other questions are the relationship between the zonally asymmetric anomalies over the Indian Ocean and the ENSO, and why the precursory signal is more remarkable in July than June and August. To examine month to month persistence of convection anomalies, the time series of monthly OLR anomalies in June, July and August over the SCS/PS, and the maritime continent, as shown in Fig. 12c and Fig. 12d. The convection anomalies over the maritime continent, particularly in the suppressed cases, indicate the same sign through the boreal summer (JJA). These suppressed convection were strong influenced by the El Niño event in the equatorial eastern Pacific, through the Walker circulation anomalies. On the other hand, the convection anomalies over the SCS/PS show weak persistency from month to month during the boreal summer. These convection anomalies over the two regions indicate that the local Hadley circulation over the western Pacific was not always intensified, when the convection over the maritime continent was suppressed as a side of the El Niño event. Thus, the El Niño event could be one of the necessary conditions for the intensification of the local Hadley circulation over the western Pacific, as the onset processes of the zonally asymmetric anomalies over the Indian Ocean.

Moreover, it is certain that the meridionally asymmetric convection anomalies over the western Pacific, convections over the northern (southern) part were enhanced (suppressed), were not appeared in all months except for July in 1982, 1994 and 1997. These convection anomalies intensified the climatological convections and the local Hadley circulation over the western Pacific during boreal summer 
(refer to Fig. 1c). However, the reason for such a meridional coupling of the convection anomalies in July have not been well understood. Meanwhile, it is well known that the Asian summer monsoon, including the convection over the SCS/PS, has large intraseasonal variation (ISV) (Nakazawa 1992; Goswami and Mohan 2001; Annnamalai and Slingo 2001). Goswami and Mohan (2001) pointed out that the activity of ISV could account for $20-60 \%$ of interannual variability of the seasonal mean in the Asian summer monsoon region. They also indicated that the interannual variations were strong over the maritime continent. These differences of interannual variability between the Asian summer monsoon region, including SCS/ $\mathrm{PS}$, and the maritime continent coincide with our result (Fig. 12). Therefore, the convection anomalies over the SCS/PS may be related to the interannual modulation of ISV in the Asian summer monsoon. However, monthly mean data couldn't resolve the ISV well, because the ISV has two preferred spectrum band, one between 10 and 20 days and the other between 30 and 60 days. Further clarifications are required.

In this manner, it is found that southern and northern part of the meridionally asymmetric convection anomalies, as a precursory signal of the zonally asymmetric anomalies over the Indian Ocean, have different interannual variability with each other. The former is probably associated with the ENSO event, and the latter associated with the modulation of the ISV of the Asian summer monsoon. Thus, it is plausible that the local Hadley circulation over the western Pacific is partly related to the ENSO event in the eastern Pacific, but also to the ISV in the SCS/PS regions. These convection anomalies over both the SCS/PS and the maritime continent should be one of the necessary conditions, respectively.

\section{Summary}

In this study, the time evolution of the zonally asymmetric anomalies of convection is described, which is a dominant pattern of interannual atmosphere-ocean variation over the Indian Ocean, utilizing OLR, SST, and wind field data of NCEP/NCAR reanalysis. In particularly, the onset processes of these anomalies are focused, with seasonal evolution and interannual variability of the large-scale convection anomalies in the Asian summer monsoon. The results of this study are summarized as follows:

1. The zonally asymmetric pattern of convection anomalies over the Indian Ocean were prominent in boreal autumn and not clear in other seasons. The features of interannual variability of OLR over the Indian Ocean were likely to be different from season to season as affected by large seasonal variability.

2 . The precursory signal of the zonally asymmetric anomalies were the positive OLR anomalies, the negative SST anomalies and strengthening of southeasterly wind follow to the coast of the Sumatra. The negative OLR anomalies over the SCS/PS were also remarkable. These meridionally asymmetric convection anomalies indicate the intensification of the local Hadley circulation over the western Pacific.

3. The intensification of the local Hadley circulation appeared only in July, but OLR and SST anomalies located the south of equator and southeasterly wind anomaly persist after July.

The intensification of the local Hadley circulation over the western Pacific between the SCS/PS, and the maritime continent in boreal summer, plays an important role on the onset processes of the zonally asymmetric anomalies over the Indian Ocean in the following autumn. The typical case appeared in 1982, 1994 and 1997, which can be described as follows:

The meridionally asymmetric convection pattern over the western Pacific is formed with the positive OLR anomalies over the maritime continent, and the negative OLR anomalies over the SCS/PS in July. These convection anomalies induced low-level cross-equatorial flow, including the southeasterly wind acceleration off the Sumatra coast. Both these low-level wind anomalies, and northwesterly in the upper layer, means intensification of the local Hadley circulation. The southeasterly wind acceleration off the Sumatra generated the zonally asymmetric SST anomalies through the dynamical effects, i.e., the southeasterly wind acceleration reduced warm water build-up and produced negative SST anomalies due to 
upwelling favorable along the Sumatra coast (Vinayachandran et al. 1999) and positive SST anomalies over the central Indian Ocean through westward advection of warm water. Then, convection anomalies over the Indian Ocean developed in response to SST anomalies and associated moisture convergence anomalies (Behera et al. 1999), till boreal winter. In addition, the reason why these anomalies ceased in boreal winter is related to the seasonal change of wind field over the south-central Indian Ocean, which turn from easterly to westerly until boreal winter, so that the easterly anomaly does not accelerate, but decelerate the westerly in boreal winter (see Fig. 1a). By contrast, the local Hadley circulation over the western Pacific is intensified in boreal summer (see Fig. 1c), as the onset phase of the zonally asymmetric anomalies. Therefore, these anomalies strongly depend on seasonal evolution of wind field around the Indian Ocean, associated with the Asian monsoon.

The zonally asymmetric convection anomalies over the Indian Ocean in the boreal autumn was closely connected to intensification of the local Hadley circulation over the western Pacific in July, associated with both suppressed convection over the maritime continent and enhanced convection over the SCS/PS. This connection was particularly remarkable in the 1994 case. The convection anomalies over the maritime continent were probably associated with the El Niño event, and those over the SCS/PS associated with the modulation of the ISV of the Asian summer monsoon. And it should be noted that the evolution of zonally asymmetric anomalies over the Indian Ocean have large seasonality. However, further study is definitely required to solve the remained problems, e.g. the role of the ISV of the Asian summer monsoon.

\section{Acknowledgment}

The authors express sincere thanks to Dr. Hiroaki Ueda of the University of Tsukuba and Dr. Jun Matsumoto of the University of Tokyo for a number of helpful discussions and useful comments. We also thank Dr. Tetsuo Nakazawa and two anonymous reviewers for giving a great effort for the improvement of the manuscript. Most of the figures were drawn using GrADS, a free soft- ware developed by Brian E. Doty, Center for Ocean-Land-Atmosphere interaction, Department of Meteorology, University of Maryland. This study was supported in part by a Grantin-Aid for Scientific Research on Priority Area (A)(1) from the Japanese Ministry of Education, Culture, Sports, Science, and Technology (No. 14204044).

\section{References}

Anderson, D., 1999: Extremes in the Indian Ocean. Nature, 401, 337-339.

Annamalai, H. and J. Slingo, 2001: Active/break cycles: diagnosis of the intraseasonal variability of the Asian summer Monsoon. Clim. Dyn., 18, 85-102.

Behera, S.K., R. Krishnan and T. Yamagata, 1999: Unusual ocean-atmosphere conditions in the tropical indian ocean during 1994. Geophys. Res. Lett., 26, 3001-3004.

Birkett, C., R. Murtugudde and T. Allan, 1999: Indian Ocean climate event brings flood to East Africa's lakes and the Sudd Marsh. Geophys. Res. Lett., 26, 1031-1034.

Cadet, D.L., 1985: The southern oscillation over the indian ocean. J. Climatol., 5, 189-212.

Cambrlin, P., 1995: June-September rainfall in north-eastern Africa and atmospheric signals over the tropics: a zonal perspective. Intl. J. Climatol., 15, 773-783.

Chambers, D.P., B.D. Tapley and R.H. Stewart, 1999: Anomalous warming in the Indian Ocean coincident with El Niño. J. Geophys. Res., 104, 3035-3047.

Chandrasekar, A. and A. Kitoh, 1998: Impact of localized sea surface temperature anomalies over the equatorial Indian ocean on the Indian summer monsoon. J. Meteor. Soc. Japan, 76, 841-853.

Gill, A.E., 1980: Some simple solutions for heatinduced tropical circulation. Quart. J. Roy. Meteor. Soc., 106, 447-462.

Goswami, B.N. and R.S.A. Mohan, 2001: Intraseasonal oscillations and interannual variability of the Indian summer monsoon. J. Climate., 14, 1180-1198.

Iizuka, S., T. Matsuura and T. Yamagata, 2000: The Indian Ocean SST dipole simulated in a coupled general circulation model. Geophys. Res. Lett., 27, 3369-3372.

Kalnay, E., M. Kanamitsu, R. Kistler, W. Collins, D. Deaven, L. Gandin, M. Iredell, S. Saha, G. White, J. Woollen, Y. Zhu, M. Chelliah, W. Ebisuzaki, W. Higgins, J. Janowiak, K.C. Mo, C. Ropelewski, J. Wang, A. Leetmaa, R. Reynolds, R. Jenne and D. Joseph, 1996: The 
NCEP/NCAR 40-year reanalysis project. Bull. Amer. Meteor. Soc., 77, 437-471.

Kawamura, R., 1998: A possible mechanism of the Asian summer monsoon-ENSO coupling. $J$. Meteor. Soc. Japan, 76, 1009-1027.

Klein, S.A., B.J. Soden and N.-C. Lau, 1999: Remote sea surface temperature variations during ENSO: evidence for a tropical atmospheric bridge. J. Climate, 12, 917-932.

Latif, M. and T.P. Barnett, 1995: Interactions of the tropical oceans. J. Climate, 8, 952-964.

Liebmann, B. and C.A. Smith, 1996: Description of a complete (interpolated) outgoing longwave radiation dataset. Bull. Amer. Meteor. Soc., 77, 1275-1277.

Meehl, G.A., 1987: The annual cycle and interannual variability in the tropical Pacific and Indian ocean regions. Mon. Wea. Rev., 115, 27-50.

- 1997: The South Asian monsoon and tropospheric biennial oscillation. J. Climate, 10, 1921-1943.

Nakazawa, T., 1992: Seasonal phase lock of intraseasonal variation during the Asian Summer Monsoon. J. Meteor. Soc. Japan, 70, 597-611.

Nicholls, N., 1989: Sea surface temperatures and Australian winter rainfall. J. Climate, 2, 965973.

Potemra, J.T. and R. Lukas, 1999: Seasonal to interannual modes of sea level variability in the western Pacific and eastern Indian Ocean. Geophys. Res. Lett., 26, 365-368.

Reynolds, R.W. and T.M. Smith, 1994: Improved global sea surface temperature analysis using optimum interpolation. J. Climate, 7, 929-948.
Saji, N.H., B.N. Goswami, P.N. Vinayachandran and T. Yamagata, 1999: A dipole mode in the tropical Indian Ocean. Nature, 401, 360-363.

Tomczak, M. and J.S. Godfrey, 1994: Regional oceanography: an introduction. PERGAMON.

Tourre, Y.M. and W.B. White, 1995: ENSO signals in global upper-ocean temperature. J. Phys. Oceanogr., 25, 1317-1332.

Ueda, H., 2001: Equatorial monsoon system as regulation for a dipole mode in the Indian Ocean. Papers in Meteorology and Geophysics, Meteorological Research Institute, 51, 147-154. - and J. Matsumoto, 2000: A possible triggering process of east-west asymmetric anomalies over the Indian Ocean in relation to 1997/98 El Niño. J. Meteor. Soc. Japan, 78, 803-818.

Villwock, A. and M. Latif, 1994: Indian Ocean response to ENSO. Proc. Int. Conf. on Monson Variability and Prediction, Vol. II, 530537.

Vinayachandran, P.N., N.H. Saji and T. Yamagata, 1999: Response of the equatorial Indian Ocean to an unusual wind event during 1994. Geophys. Res. Lett., 26, 1613-1616.

Webster, P.J., A.M. Moore, J.P. Loschnigg and R.R. Leben, 1999: Coupled ocean-atmosphere dynamics in the Indian Ocean during 1997-98. Nature, 401, 356-360.

Yasunari, T., 1987: Global structure of El NiñoSouthern Oscillation. Part II. Time evolution. J. Meteor. Soc. Japan, 65, 81-102.

$\mathrm{Yu}$, L. and M.M. Rienecker, 1999: Indian Ocean warming of 1997-98. J. Geophys. Res., 105, 16923-16939. 